\title{
CONSTRUCTING THE FLOOD EVACUATION ZONES BASED ON USER-CENTRIC TIME-DISTANCE REPRESENTATION
}

\author{
J. O. $\operatorname{Kim}^{1, *}$, S. Park ${ }^{2}$ \\ ${ }^{1}$ AICT(Advanced Institute of Convergence Technology), Suwon, South Korea - geostar1@ snu.ac.kr \\ ${ }^{2}$ Dept. of Civil and Environmental Engineering, Seoul National University, Seoul, South Korea - seula90@ snu.ac.kr
}

\section{Commission VI, WG VI/4}

KEY WORDS: Flood Evacuation Zones, Flood Evacuation Map, Time-distance Map, Multi-dimensional Scaling

\begin{abstract}
:
In the current scenario, where there is no quantitative criteria for the location, size, etc. of the shelter, an empirical study was conducted on the location distribution of the shelter considering accessibility. In this study, a safety zone that can be immediately evacuated using a pedestrian-level network is set up for each shelter. For the case area, a GIS network analysis service area analysis was used to divide the area to be evacuated to each shelter and to generate a base map in which the shelter that can reach the shelter as soon as possible can easily be identified. It is possible to provide a suitable area and evacuation route using pedestrian networks. In an urgent situation, it should be possible to get to the evacuation shelter at least as soon as possible, to avoid the high risk of flooding. Therefore, the service area that considers the flooding maps to be effective for evacuation.
\end{abstract}

\section{INTRODUCTION}

This paper aims to provide an approach to flood evacuation mapping for use as an effective resource to support evacuations prompted by a sudden inundation (Kaiser et al., 2010). In particular, we propose an algorithm to generate a flood evacuation cartogram based on an actual evacuation in real-time. The suggested time-distance map minimizes distortion by transforming the evacuation routes and preserves the topological characteristics as a whole. To empirically evaluate its application, we apply this method to Samcheok city in South Korea, As a result, optimal shelter and evacuation routes are derived by considering significant factors influencing the actual access to the facilities and escape routes, such as pedestrian elevation and the expected flood area. Moreover, the flood evacuation map provides a more effective and intuitive visualization than classic topographic maps, by relocating shelters and reshaping the routes intended for evacuation. The suggested method is significant as it provides practical flood evacuation information effectively for people in a flood situation. Our empirical results also provide helpful insights for disaster authorities or policy makers for more efficient evacuation plans.

\section{METHODS AND RESULTS}

The walking speed at the time of evacuation was assumed to be $1.3 \mathrm{~m} / \mathrm{s}$ for adults, $2 \mathrm{~m} / \mathrm{s}$ for fast walkers, and $1 \mathrm{~m} / \mathrm{s}$ for elderly people and children (Park, Kim, 2012). The evacuation time was assumed to be a minimum of 5 minutes to a maximum of 25 minutes, based on the guideline that the evacuation should finish within 25 minutes after the evacuation begins within 5 minutes after the alert is issued. Based on these assumptions, the standard values of distance according to evacuation time and pedestrian type are calculated. Therefore, when calculating the flood evacuation zone, a zone that can be reached within the next distance reference value is calculated.

The final walking time can be calculated by considering the elevation and the depth of water. Naismith's Rule is widely known for predicting walking time according to slope. The rule was devised by Naismith, a Scottish mountaineer, in 1892. The basic rule is as follows: Allow 1 hour for every 3 miles $(5 \mathrm{~km})$ forward, plus 1 hour for every 2,000 feet (600 meters) of ascent. When walking in groups, calculate for the speed of the slowest person. Therefore, the walking time $(t(m))$ of some road sections can be approximately calculated in Table 1 .

Since walking time increases with an upward slope, the modified Langmuir's law is applied to each link to calculate the travel time according to the slope. Table 1 shows the equations for walking time according to a given gradient by drawing on the modified Naismith-Langmuir law (Langmuir, 1984)

\begin{tabular}{|l|c|}
\hline \multicolumn{1}{|c|}{ Slope $\left(^{\circ}\right)$} & Equation for walking time $(\mathrm{t})$ \\
\hline Ascents (over 0) & $t(\mathrm{~m})=L(\mathrm{~m}) / v(\mathrm{~m} / \mathrm{min})+$ \\
& $0.1(\mathrm{~min} / \mathrm{m}) X \triangle E(\mathrm{~m})$ \\
Flat $(0 \sim-5)$ & $t(\mathrm{~m})=L / v$ \\
$\begin{array}{l}\text { Moderate descents } \\
(-5 \sim-12)\end{array}$ & $t(\mathrm{~m})=L / v-0.03(\mathrm{~min} / \mathrm{m}) x \Delta E(\mathrm{~m})$ \\
$\begin{array}{l}\text { Steep descents } \\
\text { under -12) }\end{array}$ & $t(\mathrm{~m})=L / v+0.03(\mathrm{~min} / \mathrm{m}) x \Delta E(\mathrm{~m})$ \\
\hline
\end{tabular}

Table 1. Modified Naismith-Langmuir law

The pedestrian network and the DEM with the $90 \mathrm{~m} \times 90 \mathrm{~m}$ resolution provided by the NSDI(National Spatial Data Infrastructure) Portal are overlaid, and elevation values are entered for each node. The gradient is then calculated using the difference in elevation of the noes from both ends of each link,

\footnotetext{
* Corresponding author
} 
and travel time can then be calculated based on this value and entered as the time cost attribute of the link.

If flooding occurs in some areas, it may restrict the evacuation. Therefore, it is necessary to consider the inundation area as an area in which passing through is restricted. That is, when specific evacuation route must pass through the flooded area, the time required to travel the route increases. According to Lee et al.(2016), walking speed during immersion is determined by the flood depth, and decreases linearly, as shown in equation (1).

$$
y=1.36-0.01 \times d
$$

where $\quad \mathrm{y}=$ walking speed $(\mathrm{m} / \mathrm{s})$

$\mathrm{d}=$ depth of water $(\mathrm{cm})$

(a)

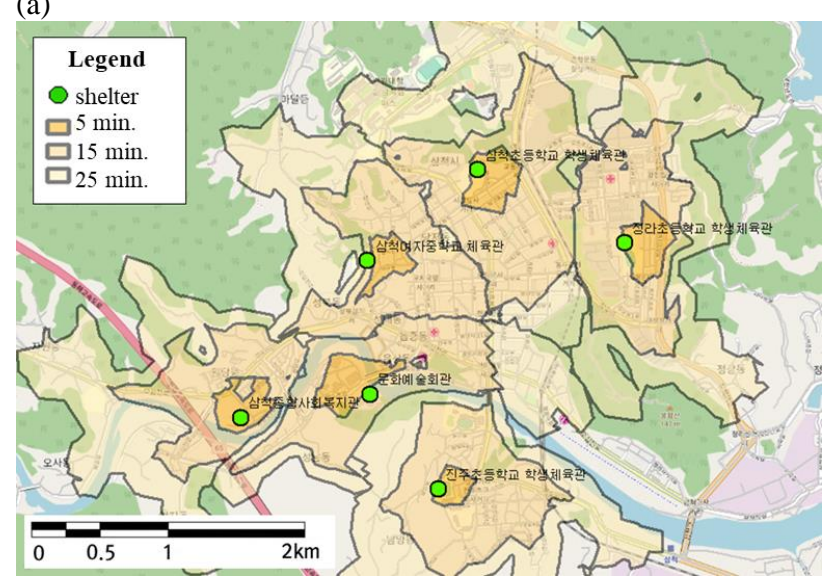

(b)

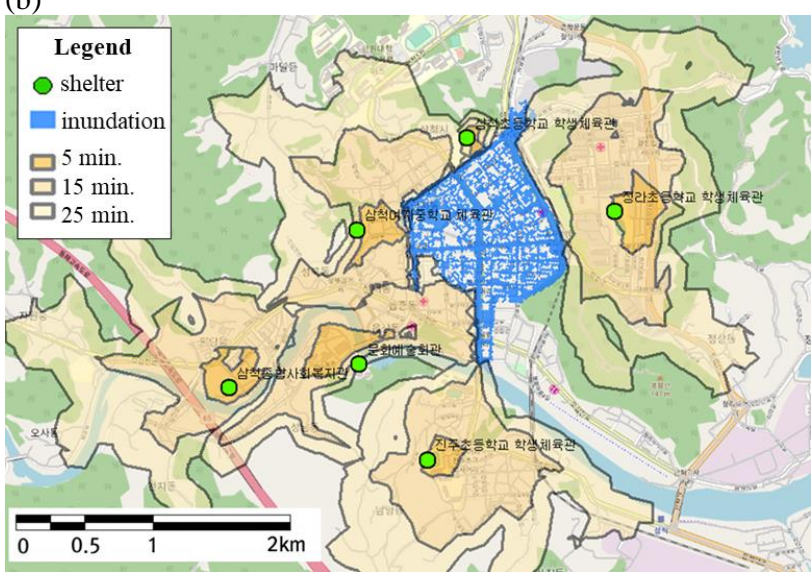

(c)

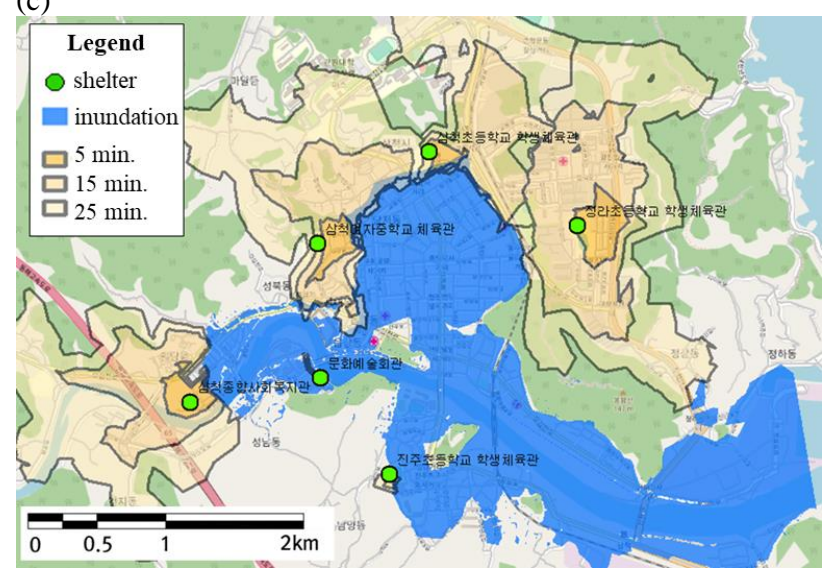

Figure 1. Figure placement and numbering
Since 1.36 in equation (1) is the average walking speed in a normal state, the value of $2 \mathrm{~m} / \mathrm{s}$, which is the fast walking standard, is applied in this study. In addition, according to Kang (2003), it is possible to awake only by relying on a fixed object in a waterway when its immersion depth reaches $0.55 \mathrm{~m}$. Therefore, the critical water depth for evacuation is set to $0.55 \mathrm{~m}$, so evacuation routes can be calculated using a detour route for areas in which flooding is expected to occur above the critical depth.

A total of 22 flood evacuation shelters have been constructed as point data in Samcheok city. The shelter layer is used as the facility data for the closest facility analysis. In the case of Figure 1(a), most residential and commercial areas are included in the evacuation area within 25 minutes unless inundation map is reflected. However, as shown in Fig. 1(b, c), most of the evacuation sites within 5 minutes have been reduced to reflect the inundation map.

\section{CONCLUSION}

Considering the inundation map, the shelter service area using time-distance representation narrows where flooding is expected, so that time required to reach the shelter is relatively long. In areas where flooding is expected, the distance traveled within the same evacuation time is shorter than areas where it is not, which narrows the service area for the same evacuation time. Based on this study, flood evacuation map using time-distance is significant, in that it provides practical flood evacuation information very effectively and intuitively for people in a real flooding situation.

\section{ACKNOWLEDGEMENTS}

This work was supported by the National Research Foundation of Korea(NRF) grant funded by the Korea government(MSIT) (No. 2019R1A2C1010976).

\section{REFERENCES}

Kaiser, C., Walsh, F., Farmer, C. J., Pozdnoukhov, A., 2010: User-centric time-distance representation of road networks. International Conference on Geographic Information Science, 85-99.

Kang, S. 2003: Study on refuge behaviour and its critical inundation depth in low area. Journal of The Korean Society of Civil Engineers 23(6B), 561-565 (in Korean with English abstract).

Langmuir, E., 1984: Mountain craft and leadership: a handbook for mountaineers and hillwalking leaders in the British Isles.

Lee, H., Hong, W., Lee, Y., 2016: A study on the evacuation speed changes according to the depth of water. Journal of the Architectural Institute of Korea Planning \& Design, 32(3), 7582 (in Korean with English abstract).

Park, J.K., Kim, D.M., 2012: Analysis of shelter service areas according to walking speed using network analysis. Journal of the Korean Society for Geospatial Information Science 20(4), 37-44 (in Korean with English abstract).

Revised May 2019 